\title{
Assessing Nurse Capacity and Workforce Development in Low Resource Settings
}

\author{
Adele A. Webb ${ }^{1 *}$, Brenda T. Spear ${ }^{2}$ \\ ${ }^{1}$ Senior Academic Director of Workforce Solutions, Capella University, USA \\ ${ }^{2}$ Campus President, Cleveland, Chamberlain University, USA
}

\author{
Article Details \\ Article Type: Mini Review \\ Received date: $21^{\text {st }}$ June, 2018 \\ Accepted date: $10^{\text {th }}$ August, 2018 \\ Published date: $30^{\text {th }}$ August, 2018
}

"Corresponding Author: Adele A. Webb, Ph.D, FNAP, FAAN, Senior Academic Director of Workforce Solutions, Capella University, USA. E-mail: adele.webb@capella.edu

Citation: Webb AA, Spear BT (2018) Assessing Nurse Capacity and Workforce Development in Low Resource Settings. J Comp Nurs Res Care 3: 127. doi: https://doi.org/10.33790/jenrc1100127.

Copyright: (C2018, This is an open-access article distributed under the terms of the Creative Commons Attribution License 4.0, which permits unrestricted use, distribution, and reproduction in any medium, provided the original author and source are credited.

\begin{abstract}
According to the World Health Organization (WHO), nurses and midwives account for about $50 \%$ of the global health workforce [1]. Given the large number of providers that this represents, it is imperative that this workforce be prepared at the highest level possible. With the attrition of nurses a growing concern, this worldwide issue is affecting the global nursing shortage in a profound way. In fact WHO predicts that the world will need an additional 9 million nurses and midwives by the year 2030 [1].
\end{abstract}

The nursing shortage is exacerbated by the lack of qualified nursing faculty. In a study by Nardi \& Gyurko [3] it was noted that the issues around the faculty shortage were multi-faceted and highlighted the need for a new approach to education models that include international collaborations to pool resources. It has been identified that in addition to new and different education models, nursing faculty need mentors in order to build their capacity and engagement [4]. In fact, Seekoe [4] identifies that mentoring can result in empowerment for the nurses, resulting in an interactional participatory relationship that allows for the mentor to actually serve as not just mentor, but also peer, creating a mutually beneficial relationship [4].

As late as 2017, Bruce, et al. [5] describe the lack of advanced skills in nurses that are needed to facilitate not just health initiatives, but also research projects and the education of other nurses. Their recommendations include forging alliances and government investment in order to develop the capacity of nurses.

In order to address the growing and concerning issue of nurse capacity and retention, a World Health Assembly resolution [6] has been issued that calls on member states and WHO to strengthen nursing and midwifery through a variety of measures. One such measure is "participating in the ongoing work of WHO's initiatives on scaling up transformative education and training in nursing and midwifery in order to increase the workforce numbers and the mix of skills that respond to the country's health needs and are appropriate to the health system context" [7].

In response to this call, the team of Webb and Spear has created a program for the education of and preparation of bedside nurses as well as nursing faculty as it relates to the WHO guidelines
Package of Essential Noncommunicable (PEN) Disease Interventions for Primary Health Care in Low Resource Settings [8]. This program, offered in three phases, is designed to improve health outcomes for the country, increase patient satisfaction, decrease attrition and prepare and support nurses for entrance into an online RN/BSN or MSN program at an accredited university.

Working with both the Ministers of Health and in-country WHO representatives, this team collaborates with nursing leadership in the countries to complete an assessment of nursing education and practice needs. This assessment includes a review of the nursing curriculum, looking for opportunities to add PEN intervention guideline material [8] as well as to strengthen gaps and further develop entry level content. Once that assessment is completed, the team travels to the country to complete an assessment of the current health care needs of the population and the current state of nursing education in the country (Phase 1). Surveys of nursing faculty and nursing staff are used to determine gaps and needs from the perspective of those in the field.

While "in-country", the team provides seminars on several topics identified as important by WHO. Specifically, content focuses on the PEN interventions [8].

During an initial visit, the topics of cardiovascular disease, diabetes, chronic obstructive pulmonary disease, cancer, HIV/TB and trauma are covered with both the bedside nurses and the nursing faculty. All seminars are framed in such as a way as to prepare all of the nurses for entrance into an online BSN or MSN program.

The two groups of nurses are then separated and the bedside nurses have seminars in prioritization and delegation, care delivery models, nursing process and safety. Interestingly, during the safety seminars, nurses have identified some practices where they have concerns and have developed plans to address topics such as patient identification, peer accountability, medication errors and communication patterns. The nursing faculty attend sessions on curriculum development, evaluation and assessment, critical thinking and clinical reasoning and evidence based practice. The last program implemented was on an island off the east coast of Africa. 
The results of the tests are below (Table-1).

\begin{tabular}{|l|l|l|}
\hline \multicolumn{3}{|c|}{ All Participants } \\
\hline Topic & Pretest & Post test \\
\hline $\begin{array}{l}\text { Cardiovascular } \\
\text { Disease }\end{array}$ & $70.2 \%$ & $100 \%$ \\
\hline $\begin{array}{l}\text { Chronic Obstructive } \\
\text { Pulmonary Disease }\end{array}$ & $65.8 \%$ & $80 \%$ \\
\hline Diabetes & $85.5 \%$ & $94.4 \%$ \\
\hline Cancer & $73 \%$ & $87 \%$ \\
\hline HIV/TB & $70 \%$ & $96 \%$ \\
\hline Trauma & $82 \%$ & $96 \%$ \\
\hline \multicolumn{2}{|c|}{ Bedside Nurses Only } \\
\hline $\begin{array}{l}\text { Prioritization and } \\
\text { Delegation }\end{array}$ & $63 \%$ & $81 \%$ \\
\hline Safety & $74 \%$ & $97 \%$ \\
\hline \multicolumn{3}{|c|}{ Nursing Faculty Only } \\
\hline $\begin{array}{l}\text { Critical Thinking } \\
\text { and Clinical } \\
\text { Reasoning }\end{array}$ & $92.9 \%$ & $98.4 \%$ \\
\hline $\begin{array}{l}\text { Evidence Based } \\
\text { Practice }\end{array}$ & $92 \%$ & $94 \%$ \\
\hline $\begin{array}{l}\text { Evaluation and } \\
\text { Assessment }\end{array}$ & $36 \%$ & $90 \%$ \\
\hline $\begin{array}{l}\text { Curriculum } \\
\text { Development }\end{array}$ & $12.6 \%$ & $100 \%$ \\
\hline $\begin{array}{l}\text { Nursing Theory and } \\
\text { Research }\end{array}$ & $62 \%$ & $92 \%$ \\
\hline
\end{tabular}

Table-1 Pretest and post test during the seminar presentations of participants

Post seminar evaluations were overwhelmingly positive and the nurses strongly agreed that the seminars were both a positive and beneficial experience.

With an eye on entrance into a higher education program, skills demonstrated during participation in the program made it abundantly clear, across countries, that participants would need assistance with writing skills and APA format. In addition, the team believes that a personalized orientation along with hands on instruction on navigating an online system and online library is essential.

At the completion of the first set of seminars, schools provide student profiles so that the team, working alongside the University, can determine which program is appropriate for each nurse. At times, evaluation can pose some issues as credit hours are not always the same as United States credit hours and registration of a nursing license can be different as well. But with diligence and cooperation, nurses are identified who are eligible for admission into an RN/BSN program or eligible for the MSN program with a concentration in nursing education.

In order to prepare the nurses for entry into the online programs, another visit to the country is made (Phase 2). The focus of this visit is to walk through an online platform, orient nurses to online education and provide seminars on writing skills, APA guidelines, nursing theory and research, success coaching and application of knowledge. In addition, any PEN interventions [8] that were not addressed in the initial visit, as well as any areas where there was not a significant increase in posttest scores, are presented as seminar topics.

Phase 3 is the entrance into an online higher education program. Once nurses in any role join the program, they are carefully guided and supported by a mentor. As the team is in close agreement with the recommendations of Seekoe [4] that a mentor is essential to each nurse's success, this assignment is carefully considered and the relationship is closely monitored. Given the time difference between the countries and the United States, dedicated enrollment advisors, student services advisors and mentors are on an "on-call" basis so that they are available when needed. Students are advised to email course faculty with issues related to courses.

Course and project work is carefully crafted to the health care needs of the local community. Working with nursing, school and government leadership, project topics are selected that have a significant return on investment for the country. Mentors are closely involved in project development and implementation and provide insight into appropriate research models in order to have successful results.

All of the nurses who have entered a degree program after completing the Webb and Spear classes have earned a degree or remain in programs and are making progress. It is the belief of this team that the pre-work of assessment and seminars, along with mentorship and support are responsible for this unprecedented success.

Plans are currently underway to determine whether the seminars on the PEN interventions [8] have resulted in improved quality of care, increased patient satisfaction, and/or a decrease in attrition. It is hypothesized that all three outcomes described herein will be on a positive trajectory.

\section{Reference}

1. World Health Organization (2018) Fact sheet: Nursingmidwifery.

2. Armstrong SJ, Rispel LC (2015) Social accountability and nursing education in South Africa. Global Health Action 8: 1-9.

3. Nardi DA, Gyurko CC (2013) The global nursing faculty shortage: Status and solutions for change. J Nurs Scholar 45: 31-326.

4. Seekoe E (2014) A model for mentoring newly-appointed nurse educators in nursing education institutions in South Africa. Curationis 3: 1-8.

5. World Health Organization (2011) Health workforce strengthening. Sixty-Fourth World Health Assembly, WHA64.6. Geneva: WHO.

6. Bruce JC, Dippenaar J, Schmollgruber S, Mphuthi DD, Huiskamp A (2017). Advancing nursing scholarship: The Mozambique model. Global Health Action, 10: 1-8.

7. World Health Organization (2011) Strengthening nursing and midwifery. Sixty-Fourth World Health Assembly, WHA64.7. Geneva: WHO.

8. World Health Organization (2010) Package of Essential Noncommunicable (PEN) Disease Interventions for Primary Health Care in Low-Resource Settings. Geneva: WHO. 